\title{
As condições geográficas dos fatos sociais *
}

\author{
Paul Vidal de La Blache
}

O estudo das condições geográficas dos fatos sociais é uma questão cuja importância encontraria poucos contraditores. Mas eu não surpreenderia ninguém dizendo que tal importância é antes pressentida que conhecida. Tanto sobre o objeto preciso da pesquisa quanto sobre o método a seguir, as idéias prescindem de clareza; as provas de uma certa confusão se encontram frequientemente nas conversações e nos escritos. Portanto, partindo primeiro de exemplos muito simples, vou tentar explicar-me sobre estes dois pontos.

É seguramente fácil encontrar casos de correlação íntima entre um fato geográfico e um fato social. A contigüidade de duas regiões, planície e montanha, onde a ordem dos trabalhos não é a mesma e onde as colheitas amadurecem em datas diferentes, torna disponíveis os trabalhadores que alugarão periodicamente seus braços. A presença de uma grande cidade faz nascer à sua porta cultivos especiais, associados a hábitos igualmente especiais, como o dos horticultores ou dos hortillons ${ }^{2}$ A ocorrência bem localizada de um produto de primeira necessidade pode engendrar consequiências sociais e políticas. $O$ mundo inteiro sabe a importância histórica que teve o comércio do sal na Baviera, na Lorena, na Francônia e alhures, a que movimentos de intercâmbio ele proporcionou em certos pontos do Saara. Fonte de riqueza e de poder para seus detentores, a posse deste bem provocava conflitos, criava relações e contribuía freqüentemente para a formação de cidades.

\footnotetext{
- Conferência feita na École des Hautes Études sociales e publicada nos Annales de Géographie, année XI, n 55, pp. 13-23, 1902. Tradução: Guilherme Ribeiro. Revisão Técnica: Rogério Haesbaert. 2 "hortillons" (do francês antigo "orteil", jardim [latim: "hortus"]) = que plantam em "hortillonnage", . cultivo praticado em terrenos alagáveis (especialmente na Picardia) entrecortados de canais que, com o uso intensivo de adubação, utiliza-se para a horticultura. (segundo o Dictionnaire Larousse de la langue française). (N.T.)
} 
Estas relações são interessantes; o historiador e o economista gostam de assinalá-las. Contudo, por mais curioso que possa ser reunir fatos deste gênero, podemos nos perguntar se eles constituem objeto de ciência, se é possível fundar sobre eles uma pesquisa sistemática e metódica. Sem dúvida não, se os encararmos isoladamente, como incidentes e particularidades. Mas não será diferente se ascendermos a uma noção mais compreensiva e mais elevada? Não há um plano geral no qual estão inseridos estes exemplos (ou outros semelhantes) dos fenômenos sociais?

Antes de responder a estas questões, creio ser útil lembrar que, nesta ordem de fatos, nossos meios de pesquisa se incrementaram notavelmente depois de meio século. Os progressos do conhecimento do globo e a colonização nos puseram em relação com um número cada vez maior de sociedades humanas em níveis muito desiguais de desenvolvimento. Estudamos seus gêneros de vida; de forma metódica, direcionamos a atenção aos meios de alimentação, vestuário, habitação, instrumentos, armas, numa palavra, sobre o conjunto de objetos no qual se exprimem os hábitos, as disposições e as preferências de cada grupo.

Constatamos assim as diversidades, cujo princípio, como podemos nos convencer, está sobretudo nas diferenças de materiais fornecidos pela natureza ambiente. Mas, por comparação, chegamos também à constatação de que, para além das variantes locais, cxistem formas de existência e modos de civilização abraçando grandes extensões e numerosos conjuntos de seres humanos.

Essas diversas formas de civilização se manifestam de uma forma concreta pelos objetos criados para seu uso - o que costumamos chamar de material etnográfico. Involuntariamente, a palavra nos faz imaginar as vitrines dos museus onde estão reunidas armas, adornos, despojos e utensílios de tribos selvagens. E não há porquê lamentar esta associação de idéias, pois ela tem por efeito incutir em nós a noção de que tanto a mais rudimentar quanto a mais refinada das civilizações é digna de atenção; que, por mais modesto que seja, elas têm seu lugar nos arquivos da humanidade. Mas a palavra, no que ela implica de sinalização característica, também é aplicável aos grandes tipos de civilização. Na alimentação, no vestuário, no mobiliário, nas construções, na arte médica da qual os chineses fazem uso, há, tomado da natureza inorgânica ou vivente, um fundo comum sobre o qual sua engenhosidade é exercida e que permanece como sua assinatura de povo. Diria mesmo que estas docas, elevadores e máquinas poderosas com as quais o americano maneja as quantidades e as massas são, no gênero de documentos etnográficos, os signos característicos de sua civilização. Nisto, como nos objetos nos quais os negróides [négritien] ou os malaios adotaram a matéria e a forma a partir da natureza vegetal que os cerca, manifesta-se um esforço de invenção e de aperfeiçoamento em relação a um determinado ambiente.

É fácil julgar que precioso reforço estas diversas expressões de indústria humana trazem ao estudo geográfico dos fatos sociais. As instituições e os costumes 
não têm forma material; porém, são coisas diretamente ligadas aos objetos que o homem moldou, sob influência do regime social ao qual é adaptada a sua vida. Estes objetos refletem hábitos que derivam do estado social ou que os inspiram. Assim, ganhamos para nossas pesquisas um nível que nos coloca no mesmo plano que elas e, graças à universalidade dos documentos fornecidos, estamos em melhor situação para compreender como - não em um caso particular, mas de forma geral e coordenada - os fatos geográficos se imprimem sobre a vida social.

Para nós, a causa que introduz a maior parte das diferenças entre as sociedades é a posição. Conforme uma região seja voltada ao isolamento ou, ao contrário, aberta às correntes da vida em geral, as relações entre os homens são bem diferentes. É a eterna antítese que surpreendia Tucídides, quando ele opunha na Grécia os povos que alcançaram o grau de civilização expresso pela palavra pólis e aqueles que ainda praticavam o modo de viver arcaico. Estas tribos que permaneceram primitivas ele ainda as encontraria lá onde as observou. Estas comunidades, encerradas em suas condições tradicionais de existência, têm, em geral, uma vida dura. Se pensarmos bem, é tanto motivo de reflexão quanto de surpresa ver, ao redor do nosso Mediterrâneo, tantos povos, dos quais muitos altamente dotados, cujos regimes sociais ainda portam a marca do isolamento. Aí se perpetua a vida de clã e de tribo, onde a autoridade política não excede o círculo em que ela pode se exercer de forma material e direta, no qual persiste o hábito de andar armado e onde se eternizam as guerras de vendetta entre famílias ou tribos.

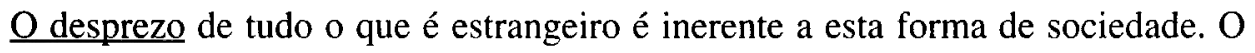
estrangeiro é protegido apenas pelos ritos de hospitalidade, cuja eficácia termina na porta da estalagem, ou pelo uso de contratos pessoais.

A montanha, a floresta, sobretudo a floresta tropical, com suas impenetráveis redes de cipós e troncos apodrecidos, as grandes extensões a transpor, seja através dos continentes, seja dos mares: eis o que tem mantido e o que ainda mantém um grande número de grupos humanos à distância uns dos outros. Há não mais que quarenta anos, existiam numerosas populações no centro da África entre as quais jamais havia penetrado nem um árabe ou um europeu. Na zona africana de florestas tropicais, a aldeia é a unidade, cada uma formando um mundo à parte na clareira que lhes coube cultivar. E, contudo, entre estes grupos que vivem num estado que parece tão rudimentar, existem os que souberam tirar engenhoso partido dos materiais fornecidos pela natureza ambiente, e cujo material etnográfico, tal como podemos estudá-lo no Museu de Berlim, não falta nem em riqueza, nem em variedade. Tanto é verdade que estamos na presença dc uma forma de sociedade decidida, desenvolvendo-se à sua maneira, dotada de uma impulsão própria! No 
Sudão, nossos oficiais puderam mesmo constatar que, ao longo do limite norte da floresta, este tipo de aldeia isolada prolifera como brotos; nas partes destacadas da floresta situam-se aldeias que têm o cuidado de erguer barricadas a fim de impedir 0 acesso às suas clareiras.

Contudo, é raro que o isolamento e o organismo social estritamente fechado em si mesmo sejam absolutos. Uma tribo pode ter uma outra ou outras em sua clientela. Os sof ou facções que dividem cada $k s a r$ no sudoeste da Argélia possuem amigos e inimigos nos outros ksour. Na própria África Central conhecemos, pelos relatos dos exploradores, este curioso exemplo de parasitismo social - lembrando certas sociedades animais - que se estabeleceu entre o pigmeu caçador e o aldeão agricultor da zona florestal tropical, no qual cada uma das partes encontra espaço para um proveitoso intercâmbio.

Acabamos de falar do isolamento que resulta das condições naturais; mas há também o isolamento desejado, metódico, cartesiano, poderíamos dizer. É aquele procurado pelos civilizados para se libertarem dos entraves de uma sociedade incômoda e realizar determinada forma social ou religiosa. Assim fizeram em 1847 os que iam buscar, na solidão do Lago Salgado ${ }^{3}$, a liberdade de se organizar segundo sua vontade - algo que lhes era recusado nos estados do Leste. Nos vales mais retirados do Altai, sobre as fronteiras da China ou mesmo além do círculo polar, nos espaços abertos da grande floresta siberiana, colônias de raskolniks viviam assim, isoladas e ignoradas - somente bem mais tarde a colonização atual, que os leva hoje a bater em retirada, revelou sua existência. Poderíamos citar também pequenas aldeias de anabatistas, que criaram uma existência à parte em alguns vales isolados ao redor do Donon? Não seria justo negar a estas escapatórias de liberação todo o seu alcance geral. A que outro sentimento obedeciam os Puritanos que, no século XVI, aportaram no litoral de Massachusetts? Não bastaria folhear Heródoto para encontrar, na colonização antiga, exemplos análogos? Tocamos assim em uma série de fatos interessantes em que podemos dizer, é verdade, que o progresso das comunicações tornam sua renovação mais difícil a cada dia. Provavelmente não é sem inconvenientes que o campo disponível para estas experiências se restrinja sem parar. Estes fenômenos de geografia social eram suscetíveis de engendrar uma série de consequiências cuja originalidade, para o sociólogo, freqüentemente não passa de um divertimento ${ }^{4}$ mas que, em certos casos, puderam servir como fermento a sociedades nascentes.

Assim como a posição, os traços físicos de uma região [contrée] estão impressos profundamente em seu estado social. A contigüidade da estepe pastoril e das terras de cultivo, do oásis e do deserto, bem como a da planície e da montanha,

\footnotetext{
${ }^{3} \mathrm{O}$ autor refere-se aqui à migração dos mórmons para a região do Great Salt Lake, em Utah, nos Estados Unidos. (N.T.)

${ }^{4} \mathrm{O}$ autor utiliza a palavra régal, que pode significar festim ou algo que causa um grande prazer. (N.T.)
} 
é um causa de relações cujo alcance político e econômico não poderia ser reconhecido sem inconvenientes. Temos aprendido isso às nossas próprias custas, na Argélia. Habituados pelos livros e teorias dogmáticas a opor, isolando-os em seus respectivos domínios, o agricultor e o pastor como duas formas de vida sem penetração recíproca, a verdadeira natureza de suas relações mútuas tem sido lentamente concebida. Tal é, contudo, o caso que se apresenta não somente sobre os limites do Saara, mas numa grande parte da África e da Ásia. Citado há pouco, aqui, o exemplo da região dos ksour permite reproduzir fielmente essas relações. Em seu ksar, parecido com o velho oppidum italiota ${ }^{5}$, entre suas muralhas atravessadas por raras portas - cujo recinto já estreito freqüentemente se subdivide, ele próprio, em setores fechados - o agricultor sedentário abriga as colheitas dos hortos que vicejam nos acessos imediatos aos pequenos canais de irrigação. Ele é agricultor e artesão; tecidos e instrumentos, a maior parte fabricados pelas mulheres, são vendidos com os grãos e as frutas no ksar onde, periodicamente, uma ou duas vezes por semana, estabelece-se um mercado. Num raio de alguns quilômetros em torno do ksar acampam sob tendas tribos que não apenas trocam sua lã e seus rebanhos com os produtos dos sedentários, mas que, elas próprias, depositam ou, seguindo o termo consagrado, ensilam ${ }^{6}$ os grãos que puderam obter pelas semeaduras feitas à mão, ao acaso de uma chuva favorável. Sua existência mais ou menos nômade, entretanto, está ligada àquela do oásis. Seus movimentos gravitam em torno dele, sem se afastar. Mas isso não é tudo. Neste emaranhado de relações fundadas sobre necessidades recíprocas, temos que levar em conta também outras tribos, que constituem a clientela longínqua, mas igualmente atraída. Sabe-se que na Argélia as tribos vizinhas do Tell executam migrações periódicas em direção ao Sul, para trocar seus produtos pastoris pelas tâmaras de que se compõe parte de sua alimentação. Cada uma está em relação com um ksar particular onde, em virtude de um contrato fielmente observado por ambas as partes, está em condições de vender e de comprar. É motivo de guerra se outras tribos tentarem suplantá-la.

Pode-se afirmar que este sistema de relações é ininteligível sem o conhecimento da fisionomia do país. Somente ela, mostrando a mescla de terras irrigadas e de terras áridas e as nuanças intermediárias que existem de um domínio a outro, retifica as concepções absolutas e restabelece a verdadeira perspectiva. Notemos bem que não se trata de um caso isolado. O modo de existência que descrevemos repousa sobre uma combinação que se repete em toda zona árida da África, bem como na Arábia ${ }^{7}$ - com a única diferença de ser, ora o sedentário, ora o nômade, ora o agricultor, ora o pastor - frequientemente mais este que aquele - que, nesta associação, faz a parte do senhor.

\footnotetext{
${ }^{5}$ Nome dado aos colonos gregos estabelecidos na Itália meridional. (N.T.)

6 "ensilotent" = conservam em silos. (N.T.)

'. Isto é bem explicado em BLUNT, Lady Anne (1881) A pilgrinage in Nejd, the Cradle of the Arab Race. Londres: Murray.
} 
Este seria o momento de falar destes oásis, eles próprios tipos tão curiosos de organização social. A própria base do edifício social muda pelo fato que a idéia de propriedade se transporta da terra para a água, tal como acontece nas regiões [contrées] onde a existência de vida vegetal depende da irrigação. Esta questão já foi abordada nesta revista pelo nosso colaborador Jean Brunhes ${ }^{8}$ que, pelos trabalhos que possui sobre este importante objeto, sem dúvida logo nos dará a oportunidade de retomá-lo. Contentemo-nos em lembrar que o que chamamos regiões áridas abarca, na América e no antigo continente, na África austral, na Austrália e no norte do Equador, uma extensão da qual não se fazia idéia há menos de meio século. Que partido o homem saberá tirar daí? Particularmente, como conseguirá utilizar os recursos da circulação de águas subterrânea? A questão se coloca com mais urgência na medida em que as regiões facilmente cultiváveis, hoje, estão quase inteiramente ocupadas; este é o nó da colonização no futuro.

Tomemos um outro exemplo, escolhido segundo condições de clima opostas. No sudeste da Ásia há regiões de chuvas abundantes onde periodicamente os rios inundam suas imediações e, ao se retirar, deixam espaços onde a água permanece por algum tempo após o fim das cheias. $\mathrm{O}$ arroz foi encontrado crescendo em estado natural nas partes desse modo submersas. Creio que a fartura de peixes e a facilidade de pescá-los nos charcos abandonados pelas cheias foi a primeira causa de atração dos grupos humanos nesses deltas ou vales fluviais. Em todo caso, a segunda causa foi a presença daquela preciosa gramínea [o arroz]. Fez-se aí a educação: com que cuidado minucioso e com que sucesso as numerosas variedades de espécies cultivadas a testemunham. Este foi o princípio de uma cultura que, pela abundância de alimentação fornecida sobre um pequeno espaço, bem como pela atenção repetida que exige, exerceu uma grande influência social. A rigor, uma família de rizicultores no Camboja pode viver em 1 hectare. A propriedade é muito dividida. Contudo, para manter as taipas dos arrozais, regular a distribuição de água, transplantar as mudas, ceifar, trilhar e descascar o arroz, é preciso uma mão-de-obra numerosa e sempre presente. Trata-se de uma série de operações que duram mais de seis meses; trabalho miúdo, de habilidade mais que de força, onde a mulher tem um grande papel. É um trabalho feito em família ou entre vizinhos. Todas as mulheres de uma aldeia se deslocam por turno a cada agricultor para proceder rapidamente e em tempo útil estas múltiplas operações. A iconografia chinesa ou japonesa nos familiarizou com estas cenas, encontrando simpáticos observadores entre alguns de nossos' residentes europeus ${ }^{9}$. O ciclo

${ }^{8}$ BRUNHES, J. (1894-1895) "Les irrigations dans la 'région aride' des États-Unis". Ann. de Géog. IV, p. 12-29; "Les irrigations em Egypte" (ibid., IV, 1897, p. 456-460); "Les grands travaux en cours d'éxecution dans la valée du Nil" (ibid., VIII, 1899, p. 242-25l); a segunda edição de "Egyptian Irrigation", de M. W. Willcox (ibid., IX, 1900, p. 265-269).

"Ver: LECLÈ̀RE, Adhémar. "La culture du riz au Cambodge". Revue Scientifique 4e. série, XIII, p. 11-109, passim. 
tradicional traz consigo festas e comemorações periódicas; ele é o quadro no qual uma multidão de gente miúda, pululando entre arrozais e paliçadas de bambu, coloca suas alegrias, superstições e esperanças.

Evitarei generalizar demais. Mas se é verdade que, nessas sociedades do Extremo-Oriente que gravitam em torno da China, seu centro e motor, a forte constituição da família e da aldeia é sua pedra angular, vê-se a relação de causa e efeito entre o modo de cultivo inspirado nas condições geográficas e a única forma verdadeiramente popular de organização social que aí se encontra. A importância deste fato, entretanto, custou a ser foi percebida. Os ingleses teriam poupado graves dissabores, no início de sua dominação da Índia, quando quiseram organizar Bengala e Bihar seguindo o princípio da grande propriedade, que lhes era caro, se tivessem tido um sentimento mais exato das condições naturais.

Pode-se objetar que os exemplos precedentes trataram apenas de sociedades pouco desenvolvidas ou parecendo fixadas em seus hábitos. A própria civilização chinesa guarda, na verdade, um aspecto patriarcal e familiar, marcado por um certo caráter de arcaísmo.

Seguramente, em nossas sociedades extremamente complicadas, a ligação é mais difícil de perceber, mas nem por isso ela deixa de existir. Por exemplo: em seus belos estudos sobre os Estados Unidos da América, o Sr. Ratzel, autor de Antropogeografia, destaca a característica original que a extensão das superfícies sobre as quais opera o americano conferiu à sua civilização. Outros observadores insistiram igualmente sobre este ponto de vista ${ }^{10}$. Com efeito, não há nada que desconcerte mais o europeu e que se imponha mais às suas reflexões. A escala das proporções não é a mesma nem para eles nem para nós. Nossos ambientes de costumes estão, geralmente, circunscritos entre o Mediterrâneo e o mar do Norte - ou seja, num intervalo cinco a seis vezes menor que aquele que o americano abarca entre seus dois oceanos. Convém acrescentar à extensão uma outra circunstância não menos importante: a fraca densidade da população. Se compararmos os Estados Unidos à província chinesa de Sichuan, uma das mais ricas e mas também uma das mais afastadas, onde, segundo o relatório de nossa Missão Lionesa, o salário diário médio de um trabalhador gira em torno de 35 centavos, temos sob nossos olhos os antípodas do mundo econômico. Para o americano, tratar-se-ia então de transportar economicamente, numa distância de $2000 \mathrm{~km}$, os produtos das pradarias aos portos do Atlântico, de tornar móveis e circulantes massas enormes de minerais e carvão: é pelo triunfo do maquinismo que ele o conseguiu. $O$ desenvolvimento da força mecânica, sob todas as suas formas (vapor ou força hidráulica) e a todos os níveis (do elevador gigantesco às aplicações mais minuciosas e delicadas), tornou-se a marca do americanismo. A existência de um instrumental de transporte incomparável não podia deixar de

${ }^{10}$ OPPEL, A. (1900) "Amérique et Américains". Ann. de Géog. VIII, 1899, p. 438-459; IX, p. 5664. 
influenciar a mentalidade americana. A estas facilidades de locomoção foram adaptados hábitos de vida que contrastam com os nossos. Os focos de produção e os grandes portos nos quais seus produtos são centralizados; a região [pays] do trigo, do ferro e dos metais preciosos; as próprias paisagens que os americanos, cansados de suas monótonas planícies, podem opor aos nossos Pireneus e Alpes, tudo se encontra separado por grandes distâncias. Contudo, estes pontos afastados retornam ao círculo de suas atividades e especulações habituais; para os americanos, eles se combinam tão naturalmente como para nós os cenários concentrados da Bretanha aos Vosges, de Flandres à Côte d'Azur. Daí as associações de idéias que aproximam, nesses espíritos, objetos para nós díspares ou muito distantes. Esta disposição os leva, nas artes, a sintetizar todos os estilos. Ela os inspira, em suas relações com a velha Europa, neste marcante ecletismo que, a despeito do alto sentimento que possuem deles mesmos, os impele a escolher, em diferentes países, o que julgam ser o melhor para incorporar à vida nacional. Deixo a outros o cuidado de dizer, finalmente, se este povo, melhor preparado que qualquer outro nas relações de grande distância, não deveria alcançar uma política geral em relação a seus costumes, na qual não seria difícil acomodar seus objetivos.

\section{III}

Trocas recíprocas se operam em todos os níveis de civilização entre as condições geográficas e os fatos sociais. Como tudo é ação e reação, tanto no mundo moral quanto no físico, há casos onde, por sua vez, a repercussão de causas sociais atua amplamente sobre a geografia. Nesse caso, não é a geografia da região [pays] que se reflete no seu regime social, mas sim o inverso. Faltaria alguma coisa de essencial nessa exposição se eu não indicasse, ao menos sumariamente, este aspecto de fatos, que é, por assim dizer, a contra-prova do que $o$ antecedeu.

Lembremo-nos qual foi, do século XVI ao XVIII, a extensão nas Índias Ocidentais e no Sul dos futuros Estados Unidos, das chamadas plantations. Áreas [contrées] que poderiam ter alimentado numerosas populações se encontravam subtraídas de suas funções naturais. Sua fertilidade era confiscada em proveito de determinados produtos especiais de alto preço no. mercado. E, como não é impunemente que se substituem as condições naturais pelas artificiais, este regime engendrou, entre outras consequiências, o tráfico de negros, ou seja, uma das formas de escravidão mais odiosas e cruéis. Frequientemente, a história destes cultivos de plantation terminou em sangrentos episódios, tanto nos Estados Unidos quanto em Santo Domingo.

As mesmas causas, felizmente em outros lugares desprovidas destas consequiências extremas, continuam a atuar em nossos dias. Sabe-se que o estadó de São Paulo, no Brasil, tornou-se o principal centro produtor de café. As terrasroxas dos Campos, solo fértil que favoreceria uma agricultura alimentar, estão 
quase que exclusivamente voltadas para aquele produto. Todas as condições sociais estão subordinadas à necessidade de produzir e elaborar, de forma lucrativa, o grão requerido pelo consumo. É por meio de grande reforço em ferramentas e pessoal que se resolve o problema. A fazenda é, também, fábrica. Nela vivem, muitas vezes, mais de mil colonos assalariados - a maior parte italianos que, ainda que recebendo altos soldos por alguns anos, isto não permite que tenham acesso à propriedade. Além disso, o extraordinariamente alto custo do crédito e da subsistência tornava impossível a existência de pequenos proprietários. Para fazer frente a estas condições, é necessário um manejo de capitais que pertence apenas a alguns fazendeiros mais importantes. Produzido em massa, manipulado no próprio local e transportado em direção ao ponto menos longínquo para diminuir o frete, o café regula toda a existência da população. O porto de Santos, em direção ao qual ele é encaminhado, tem um dos litorais do mundo mais nocivos à saúde, um local tomado pela febre amarela. É este lugar, entretanto, do qual os homens deveriam fugir tal como se foge de um cemitério, o preferido frente a outros portos menos insalubres, porém um pouco mais distantes; eis o escolhido, aquele que é freqüentado: verdadeiro paradoxo geográfico explicado pela utilidade comercial.

$O$ estudo, do qual esbocei alguns traços, poderia ser assim formulado: tradução da vida geográfica do globo na vida social dos homens. Reencontramos nestas formas de civilização a expressão de causas gerais que atuam sobre toda a superfície da terra: posição, extensão, clima etc. Elas engendram condições sociais que, sem dúvida, apresentam diversidades locais, mas que, entretanto, são comparáveis em zonas análogas. Trata-se, portanto, de uma geografia: geografia humana ou geografia das civilizações.

Contudo, o homem não está para a natureza ambiente em uma relação de dependência equiparável à dos animais e plantas. Todavia, como ele fez para que as condições de existência, contraídas em certos ambientes, adquirissem consistência e fixidez suficientes para tornarem-se formas de civilização, verdadeiras entidades que podem mesmo, em certas circunstâncias, ser transportadas para outras partes? É necessário lembrar que a força do hábito joga um grande papel na natureza social do homem. Se em seu desejo de aperfeiçoamento ele mostra-se essencialmente progressista, é sobretudo na via que ele já traçou para si, quer dizer, no sentido das qualidades técnicas e especiais que os hábitos, cimentados pela hereditariedade, desenvolveram nele. Determinado instrumento de uma tribo selvagem denota uma engenhosidade cuja aplicação a outros objetos teria sido o princípio de uma civilização superior. Este progresso não ocorreu. Com efeito, o homem não se deixa facilmente afastar de sua vida tradicional e, a menos que agitações violentas e repetidas não o arranquem de seu lugar, ele está disposto a se encerrar no gênero de existência que criou. Ele se fecha durante muito tempo numa prisão que ele mesmo construiu. Seus hábitos provêm dos ritos, reforçados pelas crenças ou superstições que ele forja como apoio. 
Eis aqui uma consideração à qual não saberiam se mostrar muito atentos todos aqueles que refletem sobre as complexas questões das relações entre a terra e o homem. Sua natureza explica certas anomalias das quais podemos, seguidamente, inferir algumas objeções. É freqüente que, entre as virtudes geográficas de uma área [contrée], algumas, que parecem evidentes, tenham permanecido estéreis ou tenham sido seguidas apenas por efeitos tardios. É preciso se perguntar, em casos semelhantes, se elas estavam em correspondência com o gênero de vida que outras qualidades ou propriedades do solo haviam aí, anteriormente, enraizado. A China, que maravilhosamente tirou partido de seu solo, nega-se, precisamente em respeito ao sustento que ela lhe deve, a explorar as riquezas, contudo enormes, de seu subsolo. Portugal tinha uma posição marítima admirável: a vantagem, até o século $\mathrm{XV}$, permaneceu quase nula para este povo de pastores e de horticultores.

Sempre ocorre que, pelo nível de fixação que realizam, estas formas de civilização constituem tipos que podemos repartir geograficamente. É possível agrupá-las, classificá-las e subdividi-las. Tal trabalho é aquele praticado pelas Ciências Naturais: como não inspirar também a geografia humana? É no plano da geografia geral que se inscreve esta forma de geografia. Sem dúvida, podemos objetar a esta concepção que ela corre o risco de induzir a generalizações prematuras. Se devemos temer este perigo, é preciso então recorrer a bons métodos para nos precavermos. Eu não saberia dar melhor conselho que a composição de estudos analíticos, monografias onde as relações entre as condições geográficas e os fatos sociais seriam encaradas de perto, sobre um campo bem escolhido e restrito. 